\title{
Symbolic Xenophobia Mirrored through the Struggle of an African Scholar in the Academic Space
}

\author{
Mishack T Gumbo
}

University of South Africa gumbomt@unisa.ac.za

\section{Doi:10.5901/mjss.2014.v5n1p555}

Abstract

In this literature study paper I dispel and confront the struggles that an African scholar is faced with in the (western) academia which mirror symbolic xenophobia. This is due to the racial and separatist behaviour that African scholars experience trying to operate in the academia. I draw more from the work of Dei (2012; 2013a; 2013b) and Kuokkanen (2010) to base my deliberations. I adopt an Africentric critical position in doing this work not to portray an attitude of hatred short of take on western systems that act as road blocks against African scholarship and indigenous knowledges.

Keywords: African scholarship, xenophobia, racism, separation, relevance, space.

\section{Background}

"African scholarship is a war". Prof. Gloria Emeagwali made this clear when she was invited by College of Education at Unisa in June 2013 during its African Connection Lecture Series. Prof. Sefa Dei reiterated this claim when he was hosted by Department of Inclusive Education of the College of Education in July 2013. The claim spells out a great task that African scholars face to find their way in the academia so much defined by western standards. I abase the discussions in this paper by importing the concept of xenophobia experienced in the social circles, into the academic sphere. My reason is that I understand the onslaught on African scholarship by colonnial systems as the mirroring of xenophobia. Xenophobia is shown through racism and separatism. It is motivated by acts of hatred and fighting for space and resources. I use the terms racism and separatism as references to xenophobia.

I note that the debate over the causes and consequences of racial differences has been at the centre of nations' social and political life (Harcourt, 2009; Valji, 2003). Non-white foreigners, Harris (2001) writes, suffer a greater risk of hostility than their white counterparts. Harris (2001) notes that in much of the international literature xenophobia is written purely in terms of racism. In subtle ways which I label "academic indecency", racial polarities are evident in academic institutions, which are aimed at discrediting African scholars the accessing of resources and stalling their academic mobility. Wa Thiong'O (in IImi, 2012, p. 149) refers to these racial dispositions as the cultural time bomb and thus explains:

The biggest weapon wielded and actually daily unleashed against collective defiance is the cultural bomb. The effect of a cultural bomb is to annihilate a people's beliefs in their names, in their language, in their environment, in their heritage of struggle, in their unity, in their capacities and ultimately in themselves.

This paper was motivated by a need for an extension of the work on African scholarship, thus backing up Dei's (2013b) assertion, i.e. to contribute to the development of African Studies. As a respondent to Dei's lecture, I raised issues that triggered this paper - the struggles of an African scholar, colonnial systems of aggrandizement, downplaying of indigenous knowledges, relevance of research, and what Semali and Maretzki $(2004$, p. 95) refer to as extinction that threatens indigenous knowledges. This paper is thus meant to encourage debates about African scholarship with an aim to motivate the combat of this extinction. Furthermore, the academy in general is very reluctant, in spite of its profession of knowledge, to expand its narrow and exclusionary epistemic foundations (Kuokkanen, 2010) to celebrate and promote indigenous knowledge systems.

Subsequent to this background I define the concepts of xenophobia, space and African scholar. Then I proceed by discussing the struggles of an African scholar in terms of doing research in academia, relevant research from an African scholarly perspective, frowning upon indigenous knowledges, tussling with a rat race in the academic work space, and 
technology as a tool to promote or to stall African scholarly work.

\section{Definition of Concepts}

\subsection{Xenophobia}

Xenophobia is a form of attitudinal, affective, and behavioural prejudice toward immigrants and those perceived as foreign (Yakushko, 2009, p. 43). From a literal perspective, this definition was demonstrated by the xenophobic attacks on foreign nationals in South Africa by South Africans in the recent past. Foreign nationals were accused of taking space and consuming the economic resources due to be enjoyed by locals. Other tendencies that fuelled the attacks on foreign nationals manifest through racism, attitude and segregation. We can adopt this understanding of xenophobia as mirrored in the academic turf evidenced by repulsive colonial atrocities inflicted on African scholars. Holloway and Keppel (2007) in their Race, Social Science, and American Thought in the Twentieth Century, relate the struggles of the black scholar as a social scientist in the Diasporan American context. These authors observe the undesired racial attitudes and much segregation prevalent in higher education, which discredit African-Americans the joys of scholarship. Because of this dispelling behaviour, black scholars faced a situation of having to develop self-reliant strategies to attend black churches and schools in order to self-educate and show responsibility towards their community through.

\subsection{Space}

Space in the academic environment can be perceived as an organised environment endowed with resources that can enable one to function and grow as a researcher, an academic, and an educator. Such space should not be defined detached from the greater social space that surrounds it. That is because in that greater social space is where communities reside which the scholar hails from and has a responsibility to serve and develop. The academic space has however been portrayed to be the coloniser's space and the tendency has been either to deliberately squeeze the African scholar to ensure his academic dwarfism, or to marginalize him. This definition is buttressed through Pamela George's demise, an Aboriginal prostitute in the Canadian context, who got killed by two colonnial descendents (Razack, (2000). Razack (2000), who followed the case closely and the manner in which it was decided, argues that Aborigininality and prostitution were elevated above the class and racial issues as an attempt to blame the murder on Pamela herself. Space in this case is viewed as a right to the coloniser, who portrays the attitude of repulsion towards the colonised. This racial attitude has been imported into the academia to discredit the indigenous scholar (Gumbo, 2001; Schick \& Denis, 2005).

\subsection{African scholar}

African scholarship is about engaging in a research agenda that truly represents and advances African ideologies and the silenced voices in the academia. The work of this scholarship is and cannot be complete without questioning the Western intellectual hegemony that enjoys disaffirmation of Africanisation. I align myself with Dei (2013b) who refers to African scholarship as engaged in an intellectual war or combat. African scholarship is about reclaiming the African scholar's space in the academia unapologetically. With this claimed space comes aspects that define Africanism, identified according to Dei as holistic, embodied learning; complex relation to culture; history; politics; identity; appreciation of the wealth of intellectual history of black scholarship; anti-colonial thinking and community work. This scholarship carries a militant mandate of African indigenous communities against the western systems of aggrandizement and marginalization. In this sense African scholarship needs courageous scholars to withstand the confrontation and discomfort fronted by western intellectualism through racism and unwillingness to accept alternative forms of knowledge and research here to be exposed in later sections.

An African scholar is a courageous scholar who refuses to succumb to this front and acquiescence; thus, he remains taut to push the African agenda. Furthermore, African scholarship is about finding or reclaiming one's centre, the innate connections, and decolonising of self (Wane, 2008). This scholarship is premised on acknowledging indigeneity as a political decolonization project motivated by a quest for ideological emancipation. Based on this stance, for any Africentric enterprise four issues that Africentric scholarship must reflect, which will be elaborated on later in this paper, must be considered - ontology/epistemology, cosmology, axiology, and aesthetics (Alkabulan, 2007). In research contexts, therefore, decolonising research means the (re)centring of indigenous knowledges, ontologies, epistemologies 
and methodologies to suit the work of African scholarship. In closing the definition of African scholar I join Summers $(2013$, p. 3) who claim that decolonising research agenda is inherently political, is never neutral, is social justice-oriented and always aims to further the self-determination of indigenous peoples and communities.

\title{
3. Doing Research in Academia as an African Scholar
}

Research is about knowledge production and development. From an academic perspective, research is a crucial subspace that defines the survival of higher educational institutions. Because of this drive, these institutions operate in a capitalistic conduit that divorces them from communities. Fernandez (1998, p. 194), supported by Summers (2013, p. 2), perceives imperialism as dangerous. He argues in this case that the modern Western world, which is a predominantly capitalist society, is characterised by competition. In this competition the human person gets reduced to the individual. This individualism defines the differences between the western world and indigenous world - individualistic notions of the western culture versus communalistic notions of the indigenous culture. Capitalism, with individualism as its bedfellow is a product of the alienating disaggregation of the community (Summers, 2013, p. 2). The western capitalistic system is the mastermind that defines the sub-space of research in academic institutions. It operates incongruently with how research is conceptualised, motivated and contextualised from an African scholarly perspective (Dei, 2013, p. 28):

- Research: a search for knowledge and a variety of ways to communicate such knowledge to others in the spirit of shared understandings of our worlds and mutual co-existence.

- Motivation: research has always been a central part of all existence and the passing on of knowledge in communities constitutes a research activity.

- Context: From time immemorial indigenous peoples have done research - they have studied, analysed, interpreted and communicated their cultural and natural surroundings to themselves and to others. Their methods of knowledge are quite different from mainstream colonial research.

According to Dei (2013a, p. 27) therefore, research does not exist outside of place or outside of history. It thus should not be a monopoly of western 'science' (Dei, 2013a, p. 28).

The western orientation to research related above, which Dei is opposed to, is a separatist one. Dei $(2013$, p. 30) writes in this regard, that in the African scholar's attempt to negotiate co-existence of western and indigenous research, western academy constantly asks the African scholar to separate his scholarship from his political activism. Dei (2013, p. 30) reacts to this approach: "But as indigenous researchers we do not stand apart from our local communities. After all, our communities help sustain us in the brutal world of the western academy and its colonial satellites all over the world". It stands to reason that doing research as an African scholar by standing aloof is a suicidal enterprise $-I$ am because my community is. The knowledge that I am pursuing and onto which I want to build is very much informed by the practices in my community. It is subsumed by the cultural element that I am part of and cannot peel myself from. That is the angle from which I make sense of the world. Western academia should take note of this and come to the party to acknowledge this difference as a way to scale off its prejudice. My connectedness to my community is demonstrated by Dei (2013, $p$. 32):

\begin{abstract}
Local peoples are seen as legitimate co-producers of knowledge, in ways not typically recognized in western research with its emphasis on the exclusive expertise of the certified researcher. Moreover, Indigenous research is aimed at sustaining local peoples' capacity to undertake their own research, under their own terms and rules of engagement. It is about building human capacities in local communities. In this way, Indigenous research asks: how do we co-produce knowledge with our communities in ways that fundamentally shift the established ways of knowledge production? In other words, how can Indigenous research challenge Western ways of knowing, including within the social sciences?
\end{abstract}

The "so-called scholarly research has always been pursued in a competitive landscape and for the most part is driven more by needs of the market than the interest of the communities under study" (Dei, 2013a, p. 34), which is misaligned to how research is conceptualised from an indigenous point of view. Indigenous research:

is driven foremost by the interests of the local communities being researched rather than the interests of the academic disciplines of the researcher of the corporate funders of the research being undertaken. What this means is that questions of the relevance of knowledge and research are and should always be at the forefront of a researcher's intellectual pursuits (Dei, 2013a, p. 34-35).

It follows that Dei (2013a, p. 35) argues that indigenous research demands that Western academics and researchers begin to rethink the what, when, how and why of social research. 
The deliberations in this section raise the issue of relevant research which I now turn to.

\title{
4. Relevant Research from an African Scholarly Perspective
}

Let me start the discussion in this section of the paper by employing the Okanagan concept of En'owkin. According to Kuokkanen $(2010$, p. 65$)$ this concept signifies a process of group commitment to find the most appropriate solutions through a respectful dialogue; En'owkin is a collective process that seeks to find ways to include those voices that are in a minority. Ngara (2007, p. 10) employs a Shona way of buttressing this point: "Kakova kanozara nemadirirano" (translated, the river is flooded by tributaries). In this case I refer to indigenous scholars' voices which represent their indigenous communities. The colonial academic system's mission has been to silence these voices rather than wanting to understand them. The true meaning of En'owkin derives from a community context characterised by extended family circles, the idea of which is not to make decisions but to hear all the voices (Kuokkanen, 2010). African scholarship is premised on this trajectory, which (Western) academic scholarship does not emphasise.

Smith (in Kuokkanen, 2010, p. 66) expresses the principle of African scholarship as follows:

\begin{abstract}
A central principle of indigenous philosophies, that of 'giving back,' forms the backbone of current research conducted by many indigenous scholars and students. It expresses a strong commitment and desire to ensure that academic knowledge, practices and research are no longer used as a tool of colonization and a way of exploiting indigenous peoples by taking (or as it is often put, stealing) their knowledge without ever giving anything back in return.
\end{abstract}

Relevant research should start with the needs and concerns of indigenous communities and let an individual researcher's be suspended. The recent round-table discourses at Unisa entertained the question of relevant research, and who decides. That is because Unisa attempts to be reflexive in pursuance of its vision: "An African university in the service of humanity". The discourses aroused pertinent aspects that concerned scholars in the likes of Dei and Kuokkanen would like to see in place - giving back to the community by way of reporting back, sharing the benefits, bringing back new knowledge and vital information to the community, taking the needs and concerns of the people into account when formulating research agendas (Kuokkanen, 2010, p. 66). This aligning of research agendas to communities "is part of the larger process of decolonizing colonial structures and mentality and restoring indigenous societies" (Kuokkanen, 2010, p. 66). Kuokkanen (2010, p. 66) states further, that other central elements of scholarly responsibilities include the distribution and sharing of the research results in an appropriate and meaningful way while recognizing that the process of sharing knowledge is a long-term responsibility involving more than sending the final report back to the community.

In Kuokkanen's (2010, p. 66) words, the participation of the community, acknowledgment of traditional genealogical and other organizing structures, relevance of research and culturally appropriate research practices and codes of conduct, capacity building as well as the commitment to the eradication of detrimental structures and elements resulting from colonization have become the hallmarks of what is today commonly known and recognized as indigenous research. However, attempts to bring indigenous knowledges onto the platform of academic discourses are confronted by resistance from academic colonialists. In academic conferences and forums it is unusual to be confronted by audible gasps of silence, averted gazes, elusive responses (Kuokkanen, 2010, p. 67) and attitudes of disdain when the word 'indigenous' is mentioned. The obvious confrontation that I have experienced is the claim that 'indigenous knowledges' do not hold in the present; that they belong to the past. My reaction has been, "indigenous people including myself, are still here, therefore indigenous knowledges still hold". It is unfortunate that certain educational policies and publications refer to indigenous knowledges as belonging to the past, encouraging this false claim. Somewhere I have raised this concern with my co-authors (Maluleka, Wilkinson \& Gumbo, 2006).

My argument is therefore questioning the hegemonic attitudes that treat the researched indigenous communities as though they were unthinking tanks from which to pour out research data without involving them actively and doing one's homework about how the research will benefit them. In concrete terms my take is an emic researcher who, in the first place shows an interest into those being researched, who if he interviews an elder in a set community, seriously thinks about questions he asks, who approaches the elder respectfully as a bearer of knowledge, who thinks about how he can involve the elder and/or community in implementing the findings to benefit the community, etc. I argue that the research activities of a colonnially inclined researcher are indifferent from those of a "xenophobian" - a disguised interest in people's stories when there is actually a subtle determination to make them die out. Ngara $(2007$, p. 8) relates this determination by claiming that the cultural hegemony of colonialism systematically destroyed indigenous systems of 
survival.

But, I maintain that like those who literally suffer xenophobic attacks are courageous to stand up and forge forward, my take on Ngara's claim is that indigenous knowledge systems and practices are still visible in indigenous context, and that he, me and other indigenous scholars are charged with a soldier's mission to defend them and make sure that they are accorded space in the academia. We refuse to be the African elites who are accused as the last bastion for cloning and recycling a colonial mentality (Ngara, 2007 citing University of British Columbia African Symposium), which is opposed to transforming the academy in Africa. We are opposed to the methodologies of disengagement and the politics of neutrality and impartiality (Battiste, 2004). Wane (2008, p. 188) relates Malidoma Some's encounter with the brutality of colonial education. Some was punished for being rebellious to the Western education system when he challenged his teachers. As a result, Some left the missionary school and went to his village. On realising that colonialism was still reigning in him, Some fought his way to go through a series of rituals in order to reclaim his African identity.

The contrast to the African agenda is the colonised meritocratic elite (African) who fails to de-clone himself off the western elitism and thus extends the colonial work of marginalising his own indigenous cultures. According to Ngara (2007, p. 8), certain people measure success in life by the distance one moves away from one's indigenous culture. This tendency is common among African scholars who have internalised the western system, shunning their Africanness. They are lamentably still blinkered by the vestiges of colonial hegemony (Ngara, 2007, p. 8) and are thus caught between a European system and a traditional knowledge base (Wane, 2008, p. 183). The questions that African scholars face are: What are they being celebrated for - is it for achieving academic accolades that have succeeded to de-marry them from their cultures, or that they have fought to contextualise their work within indigenous communities? What defines our research agenda? Does the work we are doing in any way extend the struggles of indigenous cultures, or does it defend them?

As said earlier on in this paper, Africentric scholarship reflects ontology or epistemology, cosmology, axiology, and aesthetics. In an Africentric inquiry epistemology refers to the knowledge or truth (truth embodies music, language, rituals and dance) (Alkabulan, 2007, p. 413). Epistemology contains the symbols, concepts, ideas and all other sources of knowledge (Alkabulan, 2007, p. 414). Self-knowledge is the basis of all knowledge in Africentric epistemology (Asante in Alkabulan, 2007, p. 414) which must also find meaning in the interaction between the scholar and the researched community. Alkabulan (2007, p. 414) echoes Asante's assertion, that Africentric knowledge is validated through a combination of historical understanding and intuition, that means, knowing is both rational and supra-rational. Tied to this, it is also crucial to note that emotional reaction enjoys legitimisation in the Africentric paradigm as a means of knowing and as a balance for rationality. Holistic knowledge is the hallmark that informs knowledge generation and construction. Thus, from an African context epistemology ramificates into the spiritual, emotional and holistic dimensions. Western scholarship should strive to understand this alternative instead of projecting an attitude of rejection.

Cosmology includes amongst other things myths, legends, literatures and orature (Alkabulan, 2007, p. 413). The fundamental assumptions of Africentric research are based on the African orientation to the cosmos (Asante in Alkabulan, 2007, p. 413). These assumptions embrace the physical, mental and metaphysical. The metaphysical suggests that the Africentrist's work is tied to the spiritual dimension - "African extended self is God manifesting, the human being is with God having structured consciousness through conceptual systems to be divine of supremely good" (Myers in Alkabulan, 2007, p. 413). This spiritual dimension is what western science dismisses.

Axiology is about ethics and values issues. Whilst institutions do a 'good' job of putting in place measures of ethics, which guide the research agenda, it should be noted that ethics is not importantly about what lies on paper. Rather, ethics resides in the researcher as a person. Ethics is the overarching theme that demands a researcher who works with indigenous communities to conduct himself in a way that reflects value (Summers, 2013, p. 6-7; Kovach, 2009, p. 147) for those communities, i.e. respect, collaboration, interest in the communities, giving back, etc. In African this means the researcher's reflexivity about his research activities - observation of boundaries, what aspects of knowledge to research, how to carry oneself in the presence of those researched, observance of protocol, the acceptability of the methods employed, and so on, while showing the responsibility to hold as sacred the cultural knowledges with which he engages (Kovach, 2009, p. 142). Thus, axiology implicates the approach to scientific research:

Our approach to scientific research should be in meaningful power-sharing partnership with local communities, upholding our responsibilities to local communities and addressing questions of academic responsibility and social expectations on the part of the academic researcher. Indigenous research protocols relate to the conduct of the actual research, including ways of gaining entry into local communities, what is research on, how research information is gathered and used and who has final control and ownership of the research process (Dei, 2013a, p. 33). 
I conceive of indigenous research as a community-centred, community-driven and community-focused enterprise in its processes and aims in keeping with the claims of Hodge and Lester (2005) and Schnarch (2004). Entering the community calls for the suspension of imposition in order to learn how the cultural systems that are in place work. This is about humane protocol which is anchored on the four Rs that denote responsibility, respect, reciprocity and relevance in research (Summers, 2013, p. 7). Summers $(2013$, p. 7 ) alerts us of the principles of OCAP (ownership, control, access and possession) of research and its processes the Aboriginal communities and organisations in Canada follow. I suppose these can go a long way to guide the research practitioner's work in indigenous contexts.

The Pan African model of aesthetics is premised on art and performance (Alkabulan, 2007). It is sourced from culture - images and symbols. In the context of a cosmological complex African creativity and innovation are expressed. It is the culture that provides the artist with the perspective with which to voice his or her artistic expression, an expression that speaks to the needs of the community (Alkabulan, 2007, p. 415). Spirit, rhythm, and creativity are the key criteria in discussing any aesthetic for African people (Alkabulan, 2007, p. 415).

\title{
5. Frowning upon Indigenous Knowledges
}

As stated above, visceral reactions mostly surface from non-indigenous intellectuals when the word indigenous knowledge is sounded. This is either due to ignorance and being uninterested in the concept, or a deliberate intention to keep them at the periphery of scholarly discourses. This is because of the nature of indigenous knowledges encapsulating the fundamental elements not tune with how science is perceived in western academia. "Traditionally, indigenous knowledge has not been validated vis-à-vis western scientific practices" (Semali \& Maretzki, 2004, p. 94). One of the most salient factors that caused this invalidation is that the written word has been valued more than the traditional knowledges which are mostly orally transmitted (Wane, 2008, p.185). This invalidation has reference to formal education being recognised and non-formal education not; a strategy by colonialists to discredit the indigenous education system (Wane, 2008). Dei (2002, p. 4) defines indigenous knowledges the impartation of which to the young happens by the oral mode:

\begin{abstract}
encapsulates the common-good-sense ideas and cultural knowledges of local peoples concerning the everyday realities of living. I refer, specifically, to the epistemic saliency of cultural traditions, values, belief systems and world views that, in any indigenous society are imparted to the younger generation by community elders. Such knowledge constitutes an 'indigenous informed epistemology'.
\end{abstract}

According to Dei (2002, p. 4-5), indigenous knowledge provides a world view that shapes the community's relationships with surrounding environments; it is the product of the direct experience of nature and its relationship with the social world; is crucial for the survival of society; it is based on cognitive understandings and interpretations of the social, physical and spiritual worlds; it includes concepts, beliefs and perceptions, and experiences of local peoples and their natural and human-built environments. Members of the community generate this form of knowledge, and then pass it on to the next generation through storytelling, observation, songs, ceremonies, or traditional rituals (Wane, 2008, p. 192). Now, who can be so naïve not to acknowledge the profundities of the oral transmission of this knowledge especially when taking into account that they are predominantly experientially based (an element of evidence) as it will be shown in their characteristics below?

Dei (2002, p. 5) borrows Castellano's three broad aspects of indigenous knowledge revealed through the Aboriginal knowledge, which he regards as relevant to the discourse of all indigenous knowledges:

- traditional knowledge, which is inter-generational and passed on by community elders;

- empirical knowledge, which is based on careful observations of the surrounding environments (nature, culture and society); and

- revealed knowledge, which is provided through dreams, visions and intuition.

The primary characteristics of indigenous knowledges are (Lwoga, 2011; Dei, 2002, p. 5):

- they are personal/personalized, (i.e., there are no claims to universality);

- trust in knowledge is tied to the integrity and perceptiveness of the 'speaker';

- they are orally transmitted and their sharing is directly related to the considerations of the responsibility in the use of received knowledge;

- they are experientially based and depend on subjective experiences and the inner workings of the self to generate social interpretations, meanings and explanations; 
- they are holistic and relational;

- they relate the physical to the metaphysical realms of life;

- they connect economic, cultural, political, spiritual, ecological and material forces and conditions;

- they are grounded in an awareness and deep appreciation of the cosmos and how the self/selves, spiritual, known and unknown worlds are interconnected;

- they are expressive and narrative;

- they are metaphorical in the use of proverbs, fables and tales;

- they view communalism as a mode of thought, emphasizing the sense of belongingness with a people and the land they share.

However, as much as community members and societies interact they carry with them knowledges. In the academic sphere this implies that alternative forms of knowledge should be accommodated. The term that Dei (2002, $p$. 4) borrows from Homi Bhabha to express the dynamism of knowledge systems is 'hybridity' of knowledges. I however want to caution not to treat the hybridity of Western and indigenous knowledges lightly given the historical colonial attempts to lull indigenous knowledge systems. Hybridity for me would thus mean a contestation for space for indigenous knowledge systems, i.e. to still fight for indigenous knowledges to be raised to par with Western knowledges - a war against the racial disposition towards indigenous knowledge. Dei (2002, p. 4) buttresses this claim by stating that the exclusion of indigenous knowledges from the academy within the Euro-American context of knowledge production leaves the space for the colonization of knowledges and cultures in local environments and contexts unchallenged. There MUST be a refusal by African scholars to give in to this colonial plundering of indigenous knowledges, for giving in is epistemicidal (Lebakeng, Phalane \& Dalindjebo, 2006) - our African scholarly work will not have meaning and we will lose our grip on the turf of survival. The xenophobic shadows of colonialism will thrive in the indigenous contexts if they would be left to thrive at the expense of indigenous knowledges.

I continue to argue that the attempts to discredit African scholarship and its antecedent indigenous knowledges should be understood in historical context of the coloniser's planted educational satellites (schools) which imbibe the African learner with the western notions of education and knowledge. This approach mirrors xenophobic attitudes because the idea is to silence the Africanness in the African scholar and try to import him into the western culture to either swim or perish. An account of Dei (2012, p. 103), which I share, is that his colonial education in Ghana taught him less about his own communities than other distant places, which made it difficult to relate education to his lived experiences. His situation might have even been worsened by a Diasporan context where he is operational with the African scholarship project. He has demonstrated a tough spirit of a surviving scholarship in a buffeted Diasporan context that African scholars should aspire to.

Dei's educational experiences arouse my memories about how I experienced education in the invaded indigenous context. The knowledge that I received was mostly about the 'conquering' of Africa by colonialists. For instance, in history as a subject, Africans were portrayed as inferior subjects of the Whites; in geography I learnt about patterns of European settlements and homeland systems of segregation; later on in my coursework masters in technology education I only learnt about the white technologists, designers, engineers and innovators. Regarding language, my African roots are in Zimbabwe, but I was born and raised in South Africa amongst Batswana. I learnt Setswana and can speak and write it very well. However, when I enrolled for Setswana during my undergraduate programme at Vista University (closed down during the merger of higher education institutions), African languages, including Setswana, were lectured in English teach a language through another language! That practice had a big impact on the vocabulary of these languages. As a result, when I started as a teacher at a high school I struggled to translate back to Setswana because I had to teach learners Setswana in Setswana.

The tendency of Western education systems not to accommodate indigenous forms of knowledge is pretty much informed by holism, orality and spirituality as captured in the characteristics of indigenous knowledge above - which are important aspects of indigenous knowledge. These aspects sound unscientific in academic. The positivists' view of science dismisses anything spiritual and values from the knowledge construction enterprise in order to "objectivise knowledge". It detaches knowledge construction from the constructor's value system. This is a misnomer in African. Science is a human activity that manifests in a social context; it cannot be perceived far from people as it either exists in or is perceived by them. It is unfortunate that "conventional [social science] research is still struggling to study and engage spirituality in knowledge production" (Dei, 2013a, p. 35).

The social perspective of knowledge production in indigenous contexts also raises issues of intellectual property. Dei (2013a, p. 35) argues in this respect: "It is not so much about who own the knowledge or field data as how is due recognition given to local subjects as the producers of knowledge gained". Dei (2013a, p. 35) furthers his argument, that 
the idea of knowledge through research being sold in the market place of ideas is alien to indigenous research, and that knowledge obtained through indigenous research methodologies cannot be appropriated by any one individual or body. While attempts to establish intellectual property policies is to gate-keep the colonial monopolisation and looting of indigenous peoples' intellectualism, I must hasten to discourage the westernisation of such policies. Policy makers should make an exception about intellectual property rights that reside in indigenous communities by carefully considering co-ownership. Ending this section on this note raises issues of the rat-race that have a bearing on African scholarship.

\section{Tussling with a Rat-Race in the Academic Work Space: A Recipe for Stagnation}

There have been deliberate attempts to block the development of an African scholar as a 'colleague' in the academic work space. I am using the term colleague ironically because incidences of a disguised embracing of African academics have been observed and captured in literature. The truth is that certain undesirable measures have been put in place to try to discredit an African scholar the chances of upward mobility. Frazier $(2011$, p. 2) identifies workplace issues that have been identified as barriers to the promotion and tenure for African-American faculty - lack of personal time, institutional climate, review/promotion process, marginalization of research, lack of mentoring, and covert discrimination. In my travelling to the USA this far I interacted with some African-American faculty, who shared their stories about experiencing these barring tactics with the most common ones being tenure and delayed promotion. These are not limited to Diasporan contexts only; academic institutions in Africa are known to play these segregationist tactics.

Olukoshi (2006, p. 541), in his speech which was delivered at a farewell seminar organised by the Nordic Africa Institute on 15 December 2005 in Uppsala in honour of its retiring Director, Lennart Wohlgemuth, writes:

The histor-icisation of questions under consideration is increasingly absent in Africanist discourses on Africa and, as pressures arising from career considerations, the publish-or-perish syndrome, and the culture of research as a rat race pile up, the temptation to invent false problems, resort to easy answers, and proliferate adjectival qualifications of African experiences has become all too common.

Bayaga (2011, p. 539) also notes that black lecturers are expected to prove themselves in order to establish credibility and only after they do so do they receive fair and favourable attitudes, a practice which is often in direct contrast to the white lecturers whose credibility is not questioned that vehemently. I have worked at three universities already. I have observed closely that when you are still at a lecturer position (the level mostly occupied by black lecturers), you are kept at bay and treated (by white professors) as an armature and are stuffed with academic work. The distance shortens only when you have attained your professorial title. This situation is worsened by how the work space in academia has been organised, which promotes a rat race syndrome and breeds isolation rather than team work - a picture that is misrepresentative of indigenous communities out there who operate on a communal principle. Lecturers operate in isolation because there is pressure to research, publish and present, all of which lead to competition among faculty members for merit raises, tenure, promotion and desirable course assignments (Bayaga, 2011, p. 539-540).

The separatist strategy has planted a silo mentality even in some of the African scholars who make Africa read through a lens of the west because they project a western culture in their own context. They see themselves as superior by their academic profession to the traditional philosophers who become deliberately discredited only because they have not ascended the academic ceremonial stage for their philosophical accolades to be acknowledged. African scholars that I am referring to here are easy targets of the brain drain project. Not only are they physically disposed when they have been won, but cognitively and psychologically as well. As I am writing this paper I am well aware that I have my opponents in these scholars as well whom I choose to refer to as postcolonial sell-outs. What worsens matters is the exportation of African institutions of knowledge and implanting them in universities outside the borders of Africa, and thus referring to them as African Studies. African scholars are brain drained to manage and maintain these centres. This unfortunate situation leave me with questions to ask: Who are these centres of African Studies which are detached from the African context serving? To what extent are they truly representing Africa? Could this arrangement not add to the recruiting strategy on African scholars to lull them in Diaspora? Whose project is it and who funds it? Who benefits? Olukoshi's (2006, p. 15) question is added to this list:

Although centres of African Studies were set up in the modern African university system as it began to emerge first in the period after 1945 and then more vigorously after 1960 when most African countries attained their independence, one question which was never answered satisfactorily and which remains a live one is the rationale for such studies in the post-colonial context. 
At least we have an answer to some of these questions through Olukoshi (2006), who claims that African Studies is an imperial project and imperialists control funding, thus dictating terms as sole deciders. Those that have disguised their help in Africa have actually pushed their agenda of looting, which, according to Olukoshi (2006) deprived Africanists opportunities to contribute to Africa. I argue that this act is xenophobic because its aim is to ensure the fading away of African indigeneity, at least in Africa. Universities and individual African scholars will need to adopt a more radical approach in redefining their mission in defence of indigenous knowledge systems. I am saying this because the research agenda in Africa is still dictated to by imperialists and that part of the strategy is about naming the project. Olukoshi (2006, p. 541) writes in this regard:

\begin{abstract}
Development-policy communities working under a variety of pressures demand specific kinds of research - 'practical' projects, 'quick and dirty' investigations, programmes with 'measurable developmental impact', etc. - for which they will commit resources that few institutions are able to refuse if they are to remain viable. As aid agencies have increasingly sought to shape Africanist research agendas and evolve new standards for assessing the results of research, many Africanists have felt compelled to move into instrumentalised research, often packaged as consultancies, that takes its cue from and speaks the language of policy.
\end{abstract}

Olukoshi (2006) laments the misuse of citation driven by greediness and hunger for professional networking and pushing the statistics of African Studies gurus. It is evidenced "amongst Africanists, a growing culture of a massive selfreferencing and the cross-referencing of a close-knit network of professional friends" (Olukoshi, 2006, p. 20). I am not really opposed to the academic mobility except that it is inward-looking at the expense of the local community. Active interaction with local communities is lacking to a larger extent. One's community is defined in terms of professional affiliation and to a greater degree, therefore, engagement with the local community is being frowned upon. In cases where it happens, it is mostly characterised by "a get-data" so that there is something to present at a conference, or to write and publish a paper. There is a focusing away from the local community.

Ultimately, I raise the issue of technology as a tool featuring in the struggles of African scholarship.

\title{
7. Technology as a Tool to Promote or to Stall African Scholarly Work
}

One of the powerful tools through which indigenous knowledges and communities get marginalized is through the use of technology. I want to refer to it as a "xenophobic gun" with which to shoot down indigenous knowledges. Digital technological instruments have been profusely blamed as the cause for separate development between Westernisation and Africanisation. But my take is that reactionary African scholarship is scholarship that takes advantage of the technological platform to advance its work. The cellphone technology, many models of which are quite advanced, which by casual observation seems affordable to local communities, can be used to run indigenous project campaigns. Internet can be easily accessed via these gadgets. Social media platforms like twitter, facebook, blogs, etc. are available and offer opportunities to personally design platforms and post topics that can initiate discourses on indigenous knowledges. A case in point is Professor Gloria Emeagwali's useful site (www.africanet) which shares valuable insights on African History. Unlike Olukoshi, Emeagwali has noticed an opportunity to turn the Internet weapon into a stepping stone to promote African scholarship. Thus, Olukoshi's (2006, p. 541) discomfort expressed in the following quote should be reviewed:

The dearth of organic inter-relations between Africanists and the local academic community in different African countries has been worsened by the advent of the Internet and the temptation that it has offered some to see it as a substitute for field-based longitudinal studies and the necessary investment in local networking that is crucial for the development of useful insights.

IImi (2012, p. 154) paints a bleak picture that may impact negatively on African scholarship:

For those of us fortunate enough to have physically escaped the civil war in our homeland, and settled in the West, the psychological trauma is inescapable because the darkest moments in our history are captured and interpreted by Western media.

As stated above, what IImi might not realize is that the very media being blamed provides a space for Africanists to thrive with their projects. It is a platform to engage in a corrective work. What the west has distorted through the media the militant work of African scholars is to correct. The misrepresentations of Africa in the media were to push the colonial 
agenda. It is also possible that due to non-observance of the aspects of relevant research, the approaches, theories and methods of research were scientifically unsound, hence resulting in distorted research reports. In my article Mulitcultural education and its politics (Gumbo, 2001) I question reported findings in a US-based study about the portrayal of AfricanAmerican children's thinking.

\section{In Parting}

This paper dealt with the struggles of African scholarship in the academia that presents itself in xenophobic connotations. The focus has been on issues of research, indigenous knowledges and technology. The literature consulted reveals the struggles that an African scholar is faced with. But the approach that I followed in the paper conveys a message of courage to African scholarship, which helps in making a few recommendations. Firstly, to go on with the agenda of African scholarship calls for uncompromised determination and tenacity. Secondly, African scholars should approach their work as a mandate that they are carrying of indigenous communities to combat Western domination. Finally, "hybridity" of knowledge is not impossible if Western academy will show a willingness and interest to raise indigenous knowledges to the same level in academic discourses and research as western knowledges.

\section{References}

Alkebulan, A. A. (2007). Defending the paradigm. Journal of Black Studies, 37(3), 410-427.

Batiste, M. (2004), Animating sites of colonial education: Indigenous knowledge and the humanities. [Online] Available: www.usask.ca/education/people/battistem/pdf... (October 15, 2013).

Bayaga, A. (2011). Xenophobia and racism - Elements defining collegiality: Case of a South African University students. The Journal of International Social Research, 4(17), 534-545.

Dei, G. J. S. (2012). Indigenous anti-colonial knowledge as a 'heritage knowledge' for promoting Black/African education in diasporic contexts. Decolonization: Indigeneity, Education \& Society, 1(1), 102-119.

Dei, G. J. S. (2013a). Critical perspectives on indigenous research. Socialist Studies, 9(1), 27-38.

Dei, G. J. S. (2013b). The contemporary black scholar. Paper presented to the College of Education at University of South Africa. Pretoria, South Africa.

Fernandez, E. G. (1998). 'Development or decolonization in the Andes?' In Apffel-Maglin, F. (Ed). The spirit of regeneration: Andean culture confronting western notions of development. Zed Books, London, 193-243.

Frazier, K. N. (2011). Academic bullying: A barrier to tenure and promotion for African-American faculty. Florida Journal of Educational Administration \& Policy, 5(1), 1-13.

Gumbo, M.T. (2001). Multicultural education and its politics. South African Journal of Education, 21(4), 233-241.

Harris, B. (2001), A foreign experience: Violence, crime and xenophobia during South Africa's ransition. Violence and Transition Series, Volume 5. [Online] Available: www.csvr.org.za/papers/papvtp5.htm. (October 15, 2013).

IImi, A. (2012). Living the indigenous ways of knowing: The African self and a holistic way of life. The Journal of Pan African Studies, 4(9), 148160.

Kovach, M. (2009). Indigenous methodologies: Characteristics, conversations, and contexts. Toronto: University of Toronto Press.

Kuokkanen, R. (2010). The responsibility of the academy: A call for doing homework. Journal of Curriculum Theorizing, 26(3), 61-74.

Lebakeng, J. T., Phalane, M. M. \& Dalindjebo, N. (2006). Epistemicide, institutional cultures and the imperative for the Africanization of universities in South Africa. Alternation, 13(1), 70-81.

Lwoga, E. T. (2011). A model for community participation in African libraries to preserve AlK. Paper presented at the African Indigenous Knowledge Systems Conference. Windhoek, Namibia.

Maluleka. K., Wilkinson. A. \& Gumbo. M. (2006). The relevance of indigenous technology in Curriculum 2005/RNCS with special reference to the Technology Learning Area. South African Journal of Education, 26(4), 501-513.

$\mathrm{Ngara}, \mathrm{C}$. (2007). African ways of knowing and pedagogy revisited. Journal of Contemporary Issues in Education, 2(2), 7-20.

Olukoshi, A. (2006). African scholars and African studies. Development in Practice, 16(6), 533-544.

Rozack, S. H. (2000). Gendered racial violence and spacial justice: The murder of Pamela George. Canadian Journal of Law and Society, 15(2), $91-130$.

Schick, C. \& St. Denis, V. (2005). Troubling national discourses in anti-racist curricular planning. Canadian Journal of Education, 28(3), $295-317$.

Schnarch, B. (2004). 'Ownership, control, access, and possession (OCAP) or self-determination applied to research. Journal of Aboriginal Health, $1(1), 80-95$.

Semali, L. \& Maretzki, A. (2004). Valuing indigenous knowledges: Strategies for engaging communities and transforming the academy. Journal of Higher Education Outreach and Engagement, 10(1), 91-106.

Summers, K. (2013). (Re)positioning the indigenous academic researcher: A journey of critical reflexive understanding and storytelling. International Journal of Critical Indigenous Studies. 6(1), 1-13.

Wane, N. N. (2008). Mapping the field of indigenous knowledges in anti-colonial discourse: A transformative journey in education. Race Ethnicity and Education, 11(2), 183-197.

Yakushko, A. (2009). Xenophobia: Understanding the roots and consequences of negative attitudes toward immigrants. Educational Psychology Papers and Publications, 1(1), 36-66. 